The Invisible Population of Students With Learning Disabilities in South Korea

\author{
Mikyung Shin ${ }^{1}$ and Nari Choi $^{2}$ \\ ${ }^{1}$ Department of Education, West Texas A\&M University \\ ${ }^{2}$ Department of Special and Inclusive Education, Gwangju National University of Education
}

\begin{abstract}
Author Note
We have no known conflict of interest to disclose.

Correspondence concerning this manuscript should be addressed to Nari Choi, Ph.D., Department of Special and Inclusive Education, Gwangju National University of Education, 55 Pilmun-daero, Punghyang-dong, Buk-gu, Gwangju 61204, Republic of Korea. Email: narichoi@gnue.ac.kr
\end{abstract}




\begin{abstract}
Over the last decade, there has been a rapidly declining trend in the prevalence of students with learning disabilities in South Korea. In 2019, only $1.5 \%$ of students receiving special education support were identified as having learning disabilities. This study reports on three current issues related to learning disabilities to provide a greater understanding of this declining trend in South Korea: the ongoing debate on the definition of students with learning disabilities, the continuing disagreement on the identification criteria for students with learning disabilities, and the public's limited understanding of learning disabilities. Suggestions for future directions are also discussed.
\end{abstract}

Keywords: dyslexia, issues, learning disabilities, South Korea 


\section{The Invisible Population of Students With Learning Disabilities in South Korea}

Both the definition and the prevalence rate of disability vary across different countries and their respective social contexts. Although it is estimated that over a billion people (approximately 15\% of the world's population) have some degree of disability (World Health Organization \& World Bank, 2011), in some countries, students with mild disabilities, such as learning disabilities (LD), get less attention than those with severe disabilities, meaning they are likely to be neglected (Agrawal, Barrio, Kressler, Hsiao, \& Shankland, 2019). Despite the challenges of defining and identifying students with LD, all students with disabilities must receive free, inclusive, and appropriate education at both the primary and secondary levels (United Nations, 2006).

Despite the increasing awareness of education rights throughout the life cycles of people with disabilities in South Korea, the number of students with LD, as well as their educational support, is rapidly declining, with this issue becoming a topic of heated debate across the nation. Specifically, according to special education statistics from the Ministry of Education (MOE, 2019), the prevalence rate of students with LD has been rapidly declining since 2009 . The prevalence rate of the $\mathrm{LD}$ population among the total number of students receiving special education support was $8.7 \%$ in 2009 , but, as of 2019 , the reported rate has fallen to only $1.5 \%$. Further, the number of students identified as having LD represents only $0.02 \%$ of the total school-age population (MOE, 2019).

Watching for this latest declining prevalence rate of LD in South Korea, we assume that there is a significant underrepresentation of LD. Despite the invisible prevalence of LD over time, teachers in schools have expressed that they continue to encounter at-risk and LD students in their classes (W. Kim \& J. Kim, 2016). Recent nationwide surveys in South Korea have also 
reported that about $1-5 \%$ of school-age students struggle with reading and are at risk of having LD (Y. Kim, O. Kang, Woo, \& Byun, 2015). Therefore, it is necessary to understand controversial issues related to LD in order to better comprehend the reasons behind this recent declining trend of students identified with LD in South Korea. With this in mind, we investigated whether this prevalence rate represents the "true" population with LD, or whether, in reality, students are not being correctly identified as having LD, and are thus not receiving the appropriate educational support.

\section{Issue 1. The Ongoing Debate Regarding the Definition of Students with LD}

The LD terminology has a relatively short history in South Korea. Since the LD category was first included in the Special Education Promotion Act (SEPA) in 1994, there has been continuous debate on the definition of students with LD (Choi, Shin, \& E. Cho, 2017; A. Kim, U. Kim, J. Kim, \& D. Jung, 2018). The legal definition of LD has been updated twice under special education laws. Initially, a student with LD was simply defined as "a student who has learning difficulties in a specific area such as counting, speaking, reading, or writing” (SEPA, 1994, Article 9, Clause 2). Later, with the replacement of SEPA by the Special Education Act for Individuals with Disabilities and Others (SEAIDO) in 2008, the previous definition of a student with LD was revised to "a student [who] manifests significant difficulties with learning abilities, such as listening, speaking, attention, perception, memory, and problem solving, or in academic achievement areas such as reading, writing, and mathematics due to intrinsic factors" (Article 10). However, several educators have criticized this law, claiming it is still too unclear and that in terms of educational policy and schools, several related terms are inconsistently used (A. Kim et al., 2018).

As a separate topic of LD in South Korea, there has been a rapid increase in the public's 
interest regarding dyslexia over recent years. This sudden social attention coincides with the Korea Educational Broadcasting System's broadcast regarding the issues facing children with dyslexia, "Children Trapped in Letters," in 2014. As a result of the growing awareness of the increased demands of populations who struggle to read, including students with dyslexia, each municipal and provincial office of education across the nation announced ordinances to support students with dyslexia and reading difficulties (A. Lee \& Y. Lee, 2019). Although these city ordinances were established in education offices, the policies were intended to be implemented only as a measure designed to prevent student dropouts, rather than as a district-based, schoolwide support system. For example, according to Gyeonggi-do's Ordinance for Children and Adolescents with Dyslexia and School-Dropouts (2014), "dyslexia and related difficulties" were defined as "symptoms of LD caused by dyslexia, ADHD, and depression." The purpose of this ordinance was to provide social and economic support (e.g., counseling, training, and guardian counseling related to adolescent psychological and mental stability) for children and adolescents suspended from school because of difficulties such as dyslexia. However, this ordinance did not consider the implementation of a schoolwide support system specifically designed to prevent and intervene in academic difficulties due to dyslexia. These struggling learners often require explicit and systematic instruction and accommodation within the school system, in addition to social and mental support.

There is difficulty in distinguishing between dyslexia and LD in Korea, which means the identification of LD is not yet made in a timely manner. The ongoing debate regarding the identification of students with LD is explained in the next session.

Issue 2. The Ongoing Debate on the Identification of Students with LD

Before the announcement of SEAIDO (2008), there was no consistent method for 
identifying students with LD; most of the procedures for the assessment and evaluation of students with LD were conducted by special education teachers (Woo \& J. Kim, 2005). However, with the release of the SEAIDO, the responsibility for the assessment and evaluation of eligibility for special education services was transferred to special education support centers (SESCs) under the regional education support office. With this legal mandate regarding SESCs, active efforts were made to establish nationwide criteria for identifying students with LD. Specifically, since 2010, two different criteria have been used in South Korea: one written by the Ministry of Education, Science, and Technology (MOEST, 2010), and the other by the Korean Learning Disabilities Association (KLDA, 2013). In local SESCs, these assessment criteria have been used selectively and without clear guidelines.

The MOEST (2010) guidelines on the identification criteria for students with LD emphasized three months of early intervention and referral for at-risk students in general education settings. In order to assess and identify if a student has an LD, the student must also achieve a score of $75( \pm 5)$ or higher on at least two different IQ tests, while the results of academic achievement tests (two types) should be either at least two standard deviations below the chronological average for that age group or two grade levels below their peers. Students who clearly had other disabilities (e.g., intellectual disabilities) or family and cultural concerns were excluded. Furthermore, in 2013, the KLDA suggested a revised version of the LD identification criteria. The KLDA (2013) guidelines suggested that students be referred based on low achievement (i.e., 16th percentile or one standard deviation below their peers on standardized individual achievement tests) with IQ scores higher than 70.

Since the MOEST guidelines were introduced in 2010, there has been an ongoing debate concerning the identification criteria and lack of support systems to implement the newly 
required preventive approaches aimed at identifying at-risk students before they fall too far behind their peers. Depending on both the classroom teacher's point of view and their capacity, students may or may not have been considered at risk. Additionally, given the lack of a schoolwide support system, general education teachers did not know when to refer struggling learners who consistently failed in their school tests for a full individual evaluation (W. Kim \& J. Kim, 2016). Additionally, some general education teachers were likely to give up on at-risk student referrals, owing to MOEST's (2010) complicated implementation process in the intervention system (D. Kim et al., 2012). SESCs that were in charge of the assessment of individuals with disabilities did not fully understand the new procedures; in particular, they had difficulty providing guidelines for both the referral of at-risk students (K. Jung \& J. Kang, 2015) and for distinguishing between slow learners, under-achievers, and students with LD (Y. Kim, 2012).

In addition to the difficulty of identifying students with LD, the public's understanding of LD is limited. The participants regarding the public's understanding of LD are high school students, college students, and teachers. As of yet, no study has been conducted with elementary and middle school students, or their parents, regarding the public's understanding of LD. In this regard, as a preliminary effort to expand the public's understanding of LD, we reviewed and summarized the existing voices in society.

\section{Issue 3. The Public's Limited Understanding of LD}

Despite several legislative attempts to increase the public's awareness of and improve attitudes toward individuals with disabilities (e.g., the 2019 Special Education Operation Plan and the Fifth Five-Year Development Plan for Persons with Disabilities), being labeled as having a disability is still viewed negatively in South Korea. In K. Lee's (2016) survey and social media 
analysis, more than $60 \%$ of respondents said that there was still pervasive discrimination toward people with disabilities. In particular, parents of children with disabilities said that their children experienced school violence and discrimination regarding educational opportunities (K. Kim \& S. Kim, 2015). Thus, it is likely that parents will choose to hide their children's disabilities unless appropriate services are provided for students with LD.

Furthermore, studies have shown that high school and college students have a limited understanding of LD, and do not know how to interact with their peers with LD (J. Cho, E. Kim, \& J. Lee, 2014; O. Lee \& Shin, 2019; W. Lee, 2005). In O. Lee and Shin's (2019) study, most high school respondents said they knew about or had heard the term dyslexia, but did not know about LD or other subcategories of LD (e.g., mathematics and writing LD). This dichotomous familiarity with LD terminology is a problem. It is highly likely that the population either has misconceptions of LD or thinks that dyslexia is unrelated to, or not a subcategory of, LD. Teachers also demonstrated somewhat negative and low perceptions of students with LD in comparison to students with learning difficulties; they reported having difficulty evaluating and teaching students with LD (Byon \& Park, 2013). With this pervasive lack of understanding of and negative attitudes toward people with LD, the current declining trend of recognizing LD will continue to manifest in South Korea.

In the near future, opinions from more diverse stakeholders should be gathered. Teachers, parents, and both elementary and middle school students can share their understanding of disabilities, in particular LD, in order to raise public's awareness and provide foundations for establishing special education policies for the identification procedures of LD. 


\section{Conclusion and Suggestions for Future Directions}

Despite improvements in special education laws in South Korea, there is still a lack of understanding of LD, as well as the continuous debate regarding the definition and identification criteria of students with LD. This has led to a rapidly declining identification of students with LD. We suggest some potential pathways to address this declining trend.

To assess and educate students with LD, all school personnel, including administrators, general education teachers, and special education teachers, should cooperate in extending efforts to support struggling learners. Thurlow, Quenemoen, and Lazarus (2019) emphasized the power of shared beliefs and support systems for students in inclusive settings. By sharing the responsibility for struggling learners and providing a schoolwide support system, all students, including those with LD, would receive more opportunities to learn. Furthermore, we must also increase the availability of services and well-trained personnel in SESCs, as these institutions presently suffer from a shortage of competent special education employees. This requirement is essential because these centers play a vital role in the provision of special education services and the diagnosis and identification of students with LD.

It is important to establish persistent legislative efforts for students with LD. Several Korean special education laws have been enacted since 1977, each of which has envisioned the rights of people with disabilities. Despite the establishment of the recent city regulations on supporting child and adolescent students with dyslexia, local ordinances provide inconsistent support for these students. Some offer support programs for students with LD, while others lack data-based intervention plans and systems. To address this issue, it is vital that government officials and educational leaders first understand the nature of LD (Gartland \& Strosnider, 2018), and that efforts should be made to execute policies and turn them into action plans. 
Finally, another urgently needed task is to promote disability awareness among the public and improve attitudes toward individuals with disabilities. K. Lee (2016) reported that, in South Korea, the public still holds negative views about people with disabilities. We all need to enhance our understanding of each individual's strengths and limitations, including people with disabilities. School teachers, parents, and individuals should collaborate to create an inclusive society that is accessible to everyone. 


\section{References}

Agrawal, J., Barrio, B. L., Kressler, B., Hsiao, Y. J., \& Shankland, R. K. (2019). International policies, identification, and services for students with learning disabilities: An exploration across 10 countries. Learning Disabilities: A Contemporary Journal, 17, 95-114.

Byon, C. S., \& Park, W. K. (2013). Elementary teachers' perception toward students with disabilities or underachievers. The Korean Journal of Visual Impairment, 29, 177-200.

Cho, J.-B., Kim, E.-H., \& Lee, J.-S. (2014). A study on the recognition of university students on children with learning disabilities. The Journal of Elementary Special Education, 16, 89101.

Choi, N., Shin, M., \& Cho, E. (2017). Policies and issues surrounding the identification of students with learning disabilities in South Korea. International Journal of Special Education, 32, 439-457.

Gartland, D., \& Strosnider, R. (2018). Learning disabilities: Implications for policy regarding research and practice: A report by the National Joint Committee on learning disabilities. Learning Disability Quarterly, 41, 195-199.

https://doi.org/10.1177/0731948718789994

Gyeonggi-do’s Ordinances for Suspending Children and Adolescents. (2014). Ordinance No.

4733. Retrieved from

http://www.elis.go.kr/newlaib/renew_laibLaws/h1126/laws_list_new.jsp?lawsNum=4100 0023006005\&isClose $=0$

Jung, K., \& Kang, J. (2015). A study on field responses about the diagnosis and evaluation of learning disabilities: Focus group interview with experts who work at a special education support center. Special Education Research, 14, 193-216. 
https://doi.org/10.18541/ser.2015.10.14.3.193

Kim, A., Kim, U., Kim, J., \& Jung, D. (2018). Who are students with learning disabilities, dyslexia, low achievement, and learning support needs? Is the current educational support all right? The role and the task of special education. Korean Journal of Special Education, 53, 1-21. https://doi.org/10.15861/kjse.2018.53.1.1

Kim, D., Koh. H., Shin. J., Kim, I., Kim, B., \& Lee, K. (2012). The exploratory study for screening and identification processes of learning disabilities at special education support center: Focused on current condition and improvement method. Asian Journal of Education, 13, 253-283. https://doi.org/10.15753/aje.2012.13.3.010

Kim, K., \& Kim, S. (2015). Human rights violation of students with disabilities in inclusive education. Special Education Research, 14, 57-79.

Kim, Y.-S. (2012). Survey on the realities of identification process for students with learning disabilities. The Korea Journal of Learning Disabilities, 9, 53-79.

Kim, Y., Kang, O., Woo, J., \& Byun, C. (2015). A study on standardizing a dyslexia screening checklist and statistical estimation of Korean students with dyslexia. Korea Journal of Learning Disabilities, 12, 21-45.

Kim, W., \& Kim, J. (2016). Definitions and interventions of children at risk for disabilities: Experiences and perceptions of general and special education teachers. Korean Journal of Special Education, 51, 1-32. https://doi.org/10.15861/kjse.2016.51.3.1

Korea Educational Broadcasting System. (2014, April 30). Children Trapped in Letters [Press release]. Retrieved from https://www.youtube.com/watch?v=1v6zoR6VXWo Korean Learning Disabilities Association. (2013). The criterion for selecting students with learning disabilities. Gyeongju, Republic of Korea: Author. 
Lee, A., \& Lee, L. (2019). An analysis of the local ordinance for supporting to students with dyslexia. Korean Journal of Special Education, 54, 91-119. https://doi.org/10.15861/kjse.2019.54.1.91

Lee, K. (2016). The analysis of the general public's interest level and sentiments toward people with disabilities based on social big data and offline surveys. Special Education Research, 15, 81-110. https://doi.org/10.18541/ser.2016.11.15.4.81

Lee, O., \& Shin, M. (2019). A national online survey of South Korean high school students' understanding of learning disabilities. Learning Disability Quarterly, 42, 46-59. https://doi.org/10.1177/0731948718790062

Lee, W. R. (2005). A study on recognition of university students about learning disabilities. Journal of Special Education and Rehabilitation Science, 44, 43-61.

Ministry of Education. (2019). 2019 special education statistics. Sejong, Republic of Korea: Author.

Ministry of Education, Science, and Technology. (2010). Selection requirements and procedures for students with LD. Seoul, Republic of Korea: Author.

Siegel, L. S. (2006). Perspectives on dyslexia. Paediatrics and Child Health, 11, 581-587. https://doi.org/10.1093/pch/11.9.581

Special Education Act for Individuals with Disabilities and Others. (2008). Act No. 8852. Retrieved from https://elaw.klri.re.kr/eng_mobile/viewer.do?hseq=46388\&type=part\&key=16

Special Education Promotion Act. (1994). Act No. 4716. Retrieved from http://law.go.kr/LSW/lsInfoP.do?1siSeq=54184\&anc Yd=19940107\&ancNo=04716\&efY $\mathrm{d}=19940701 \&$ nwJoYnInfo=N\&efGubun $=$ Y\&chrClsCd=010202\#0000 
Thurlow, M.L., Quenemoen, R.F., \& Lazarus, S.S. (2019). Leadership to improve student outcomes. In J. B. Crockett, B. Billingsley, \& M. L. Boscardin (Eds.), Handbook of leadership and administration for special education (2nd Ed.). London: Routledge.

United Nations. (2006). Convention on the Rights of Persons with Disabilities. Retrieved from https://www.un.org/development/desa/disabilities/convention-on-the-rights-of-personswith-disabilities.html

Woo, J., Kim, J. (2005). The realities and improvement plan of special class students' diagnosis and evaluation for selection and placement: Focused on the special classes of elementary schools. Journal of Special Education \& Rehabilitation Science, 6, 201-228.

World Health Organization \& World Bank. (2011). World report on disability. Geneva, Switzerland: World Health Organization. 